\title{
Pharmacopoeial HPLC methodology improvement: A case study of piroxicam
}

\author{
Mikaelly P. Caet ${ }^{\mathrm{a}}$, Millena A. Monsores ${ }^{\mathrm{a}}$, Anna Karolina M. S. Machado ${ }^{\mathrm{a}, \mathrm{b}}$, Thiago Barth ${ }^{\mathrm{a}, \mathrm{b}}$, Maximiliano S. Sangoi ${ }^{\mathrm{a}, \mathrm{b}}$ \\ Vítor Todeschini ${ }^{\mathrm{a}, *}$ \\ ${ }^{a}$ Curso de Farmácia, UFRJ, Macaé-RJ, Brasil; ${ }^{b}$ Programa de Pós-graduação em Produtos Bioativos e Biociências, \\ UFRJ, Macaé-RJ, Brasil.
}

\section{*Corresponding author: vitor_todeschini@hotmail.com}

In the present study, a simple, stability-indicating and cost-effective reversed-phase high performance liquid chromatography (HPLC) method was developed and validated for the determination of piroxicam in commercial and masterful formulation capsules as an alternative to existing methods. The improved HPLC method was carried out on a $\mathrm{C} 18$ column $(150 \mathrm{~mm} \times 4.6 \mathrm{~mm}$ i.d., $5 \mu \mathrm{m})$, maintained at $30^{\circ} \mathrm{C}$. The mobile phase consisted of a solution of triethylamine $0.3 \% \mathrm{pH} 3.0$ and acetonitrile (70:30; v/v), flow rate of $1.0 \mathrm{~mL} / \mathrm{min}$, and using photodiode array (PDA) detection at 248 $\mathrm{nm}$. The chromatographic separation is obtained with retention time of $6.8 \mathrm{~min}$, presenting adequate system suitability parameters for HPLC analysis. Validation parameters such as the specificity, linearity, matrix effect, precision, accuracy and robustness were evaluated in accordance with the ICH Q2(R1) and Brazil RDC 166/2017 guidelines, giving satisfactory results within the acceptable range. The proposed method was successfully validated and applied for piroxicam analysis, contributing to improve the quality control and stability studies, and can be used as easy, accurate, low timeconsuming alternative to pharmacopeial quantification methodology of drug.

Keywords: method improvement; piroxicam; high performance liquid chromatography; validation. https://doi.org/10.22456/2527-2616.108512

\section{Introduction}

The compendial methods from $\mathrm{BPh}$ (Brazilian Pharmacopeia) are widely used in pharmaceutical drug product and raw materials testing. However, some methods can be improved, obtaining better results, reducing costs and generating less waste, reducing the impact on the environment by using excessive amounts of organic solvents, thus allowing its application in stability studies. Thereby, the $\mathrm{BPh}$ methods must be under continuous revision to improve existing procedures and to improve the compliance of drug product monographs with current scientific and regulatory standards (1).

In this study, piroxicam monograph from $\mathrm{BPh}$ was considered for improvement investigations. BPh suggest the analysis of piroxicam capsules by spectrophotometry with detection at $354 \mathrm{~nm}$ (Method I) and by high performance liquid chromatography (HPLC) with the following conditions (Method II): C18 column (300 mm x $3.9 \mathrm{~mm}$ i.d., $10 \mu \mathrm{m}$ ) at room temperature, mobile-phase composed by methanol and citrate-phosphate buffer $(60: 40, \mathrm{v} / \mathrm{v})$ flow rate of $2 \mathrm{~mL} / \mathrm{min}$, with UV detection at $248 \mathrm{~nm}$, and injection volume of $10 \mu \mathrm{L}$ (1). USP piroxicam capsules monography presents small differences, presenting same stationary phase, the mobilephase is composed by methanol and citrate-phosphate buffer $(45: 55, \mathrm{v} / \mathrm{v})$ flow rate of $1.2 \mathrm{~mL} / \mathrm{min}$, with UV detection at $254 \mathrm{~nm}$, and injection volume of $25 \mu \mathrm{L}$ (2). These settings can be expensive, aggressive to the equipment and does not guarantee the ability to degradation products analysis and application in drug stability studies. There are some published methods for quantitation of piroxicam in pharmaceuticals, performed in different analytical conditions, but commonly using buffer solution as mobile phase (3-11).

Oxicam nonsteroidal anti-inflammatory drugs (NSAIDs) are a group of structurally closely related substances with anti-inflammatory, analgesic and antipyretic activities $(12,13)$. It acts by inhibiting the activity of the cyclooxygenase enzymes $\mathrm{COX}-1$ and $\mathrm{COX}-2$ in a nonselective way, being associated on the biosynthesis of prostaglandins and thromboxanes $(14,15)$. They have a weakly acidic character and are extensively bound to plasma proteins $(13,16)$. NSAID use must be carefully monitored, taking into consideration the patient's age, comorbid conditions, and risk of adverse effects, particularly gastrointestinal bleeding and renal insufficiency (17). Piroxicam, the most widely used oxicam, is chemically described as 4-hydroxy-2-methylN-2-pyridinyl-2H-1,2-benzothiazine-3-carboxamide-1,1dioxide (Figure 1). Piroxicam is a long-acting drug with a long terminal elimination half-life enabling the drug to be administrated once daily, making it useful when NSAID treatment is required for a chronic condition (13). It is well absorbed after oral administration and is widely used in the treatment of rheumatoid arthritis, osteoarthritis and traumatic hematomas (18).<smiles>CN1C(C(=O)Nc2ccccn2)=C(O)c2ccccc2S1(=O)=O</smiles>

Figure 1. Chemical structure of piroxicam. 
Quality control (QC) through analytical techniques ensures the safe and effective use of the medicines (19). HPLC is one of the most widely used analytical techniques for drug analysis because of its ability to separate and analyze large amounts of compounds in a short time with high resolution, efficiency, and sensitivity (20). To ensure that the method is suitable for its purpose, the analytical method needs to be validated. Accordingly, the HPLC method has been validated as recommended by the International Conference on Harmonization (ICH) and Brazilian RDC 166/2017 guidelines $(21,22)$.

Considering the improvement and advances in analytical techniques, a simple, fast, cost-effective and stabilityindicating HPLC method was developed and validated for the determination of piroxicam in commercial and masterful pharmaceutical capsules. Responses obtained by validated HPLC method was compared to compendial HPLC and UV spectrophotometric methods, contributing to establish new alternatives with advantages for the QC and stability studies of the pharmaceutical formulations and assuring the therapeutic efficacy.

\section{Experimental}

\section{Chemicals and reagents}

The standard substance of piroxicam was acquired from the Pharmacopeia Comércio e Importação Ltda (Barueri, SP, Brazil), with purity of $99.5 \%$ (determined by HPLC). Capsules dosage forms of four different suppliers of piroxicam $20 \mathrm{mg}$ were used. Sample A corresponds to the commercial capsules and samples B, C and D were obtained from locally masterful pharmacies. All substances were used within the expiration date. Sodium hydroxide, sodium phosphate, citric acid and HPLCgrade triethylamine, phosphoric acid $85 \%$, methanol and acetonitrile were obtained from Tedia Company Inc (Fairfield, OH, USA). Ultrapure water (Milli-Q® Direct Water Purification System, Merck Millipore Corporation, Darmstadt, Germany) was used for all the analyses.

\section{Standard and sample solutions}

The standard solution was prepared by weighing standard substance of piroxicam (equivalent of $25 \mathrm{mg}$ ) and diluted to volume with methanol, obtaining the concentration of $1000 \mu \mathrm{g} / \mathrm{mL}$. The reference solution was stored at $2-8{ }^{\circ} \mathrm{C}$, protected from light and daily diluted to an appropriate concentration in mobile-phase daily for HPLC analysis and in $0.1 \%$ sodium hydroxide solution for UV analysis. To prepare the sample solutions for HPLC analysis, twenty capsules containing $20 \mathrm{mg}$ of piroxicam were accurately weighed. An appropriate content of the powder was transferred into an individual $100 \mathrm{~mL}$ volumetric flask, diluted to volume with methanol, kept in vortex for $5 \mathrm{~min}$, sonicated for $10 \mathrm{~min}$ and filtered through a 0.45 $\mu \mathrm{m}$ membrane filter (Millipore), obtaining theoretical concentrations of $50 \mu \mathrm{g} / \mathrm{mL}$. For UV analysis, $25 \mathrm{mg}$ of piroxicam were accurately weighed and transferred into an individual $250 \mathrm{~mL}$ volumetric flask, diluted to volume with $0.1 \%$ sodium hydroxide solution, obtaining theoretical concentrations of $10 \mu \mathrm{g} / \mathrm{mL}$.

\section{UV instrument and procedure}

The UV-Visible double-beam spectrophotometer, model Lambda 35 (PerkinElmer, Singapore) was used in this study. The instrument was equipped with $1 \mathrm{~cm}$ quartz cells, with PerkinElmer UV WinLab software (version v5) for instrument control, data acquisition and analysis. All spectra were recorded in the range $200-400 \mathrm{~nm}$ with $0.1 \mathrm{~nm}$ intervals, at scanning speed of $960 \mathrm{~nm} / \mathrm{min}$, with a fixed slit to lead to a spectral resolution of $1 \mathrm{~nm}$. Following the official compendium (Method I), the absorbance measurements were performed at $354 \mathrm{~nm}$, using the $0.1 \%$ sodium hydroxide solution as blank solution (1).

\section{HPLC instrument and procedures}

HPLC analysis were performed on a Prominence HPLC system (Shimadzu, Kyoto, Japan) equipped with a CBM20A system controller, an LC-20AD pump, a DGU-20A degasser, a SIL-20A autosampler and an SPD-M20A photodiode array (PDA) detector. The peak areas were integrated automatically using HPLC solution software. The compendial HPLC experiment (Method II) were performed on a RP C18 Phenomenex column $(300 \times 3.9$ $\mathrm{mm}$ i.d.; $10 \mu \mathrm{m})$. The system was operated isocratically at room temperature using as mobile phase consisted of methanol and citrate-phosphate buffer $(60: 40 ; \mathrm{v} / \mathrm{v})$, flow rate of $2.0 \mathrm{~mL} / \mathrm{min}$, and using PDA detection at $248 \mathrm{~nm}$. The injection volume was $10 \mu \mathrm{L}$ (1). The alternative HPLC (Method III) method were carried out on a RP C18 Shimadzu column $(150 \times 4.6 \mathrm{~mm}$ i.d.; $5 \mu \mathrm{m})$ maintained at $30{ }^{\circ} \mathrm{C}$. The mobile phase consisted of acetonitrile and triethylamine solution $0.3 \% \mathrm{pH} 3.0(30: 70 ; \mathrm{v} / \mathrm{v})$, flow rate of $1.0 \mathrm{~mL} / \mathrm{min}$, with detection at $248 \mathrm{~nm}$ using PDA detector and injection volume of $10 \mu \mathrm{L}$.

\section{Validation of the alternative HPLC method}

In order to demonstrate the feasibility of the alternative HPLC method, it was validated by determining the following parameters: specificity, linearity, matrix effect, precision, accuracy, LOD, LOQ, and robustness following the guidelines $(21,22)$.

\section{Forced degradation studies}

A stability-indicating method is defined as an analytical method that accurately quantifies the active ingredients without interference from degradation products, process impurities, excipients or other potential impurities (23). The stability-indicating capability of the alternative HPLC method was determined by subjecting a solution $(1000 \mu \mathrm{g} / \mathrm{mL})$ to accelerated degradation by acidic, basic, thermal, oxidative and photolytic conditions to evaluate the interference in the quantitation of piroxicam. A sample solution prepared in $2 \mathrm{M}$ hydrochloric acid $(\mathrm{HCl})$ 
was used for acidic hydrolysis, and a sample solution in 2 $M$ sodium hydroxide $(\mathrm{NaOH})$ for basic hydrolysis evaluation. Both solutions were maintained at room temperature and neutralized with acid or base prior to analysis, as necessary. For thermal stress testing, the reference solution was sealed in a glass vial and placed in the thermostatic block at $40^{\circ} \mathrm{C}$. The oxidative study was induced by storing the solution in $15 \%$ hydrogen peroxide $\left(\mathrm{H}_{2} \mathrm{O}_{2}\right)$, at ambient temperature, protected from light. Photodegradation was induced by exposing the sample in the photostability chambers to near UV-C (254 nm) light. All tests were performed during $24 \mathrm{~h}$. After subjecting the samples to stress studies, they were withdrawn and diluted with the mobile-phase solution to final theoretical concentrations of $50 \mu \mathrm{g} / \mathrm{mL}$.

\section{Quality control assessment}

The QC tests were performed following the method described in General Methods and Piroxicam $\mathrm{BPh}$ monograph (1). For mass uniformity evaluation, twenty capsules from each sample were individually weighed and the average-weight was determined. The disintegration time was determined using 6 capsules in a disintegration apparatus (Nova Ética, São Paulo, Brazil) without discs at $37{ }^{\circ} \mathrm{C}$, in water. The dissolution test (Nova Ética, São Paulo, Brazil) was carried out in $900 \mathrm{~mL}$ of $0.01 \mathrm{M}$ hydrochloric acid, using the basket apparatus were at 100 rpm. A $10 \mathrm{~mL}$ aliquot of sample was collected after 45 minutes, filtered, and the absorbance in the region of ultraviolet were determined at $242 \mathrm{~nm}$. The dose uniformity test was performed by the content uniformity approach. Thus, the content of 10 capsules was determined based on individual assay using UV method.

\section{Sample analysis}

For quantitation of piroxicam in commercial and masterful pharmaceutical capsules, the respective working sample solutions were diluted to appropriate concentrations of $50 \mu \mathrm{g} / \mathrm{mL}$ and $10 \mu \mathrm{g} / \mathrm{mL}$ and analyzed by HPLC methods and UV method, respectively. In all cases, the drug assay (\%) was calculated against the reference substance and the obtained results were compared statiscally by ANOVA.

\section{Results and Discussion}

\section{Alternative HPLC method development}

To develop the best analytical method for its intended use, a fully integrated method development process such as the selection of column, mobile phase, and detection were considered to ensure the methods are robust, consistent, and easy to use.

The effect of the composition of the column and mobilephase were investigated considering the selectivity and sensitivity of the assay, stability studies and the separation between the drug and degraded products formed during forced degradation studies. Thus, different columns technologies, length and kind of the carbon-chain attached to the silica surface such as C18, monolithic and FusedCore particle technology were tested. For mobile phase investigation, distinct proportions of organic solvent (acetonitrile and methanol) and aqueous solvent were tested, analyzing the use of buffer solutions, different $\mathrm{pH}$ values and triethylamine additive.

The characteristics of the column, such as: porosity, diameter, particle size and length, directly affect the chromatographic resolution, efficiency and pressure of the equipment. In addition to influencing the flow resistance of the mobile phase. Therefore, the choice of phases should seek the best chromatography performance with selectivity, reproducibility and agility in the analysis $(20,24,25)$.

\section{System suitability testing}

The system suitability tests should be used for choosing the method conditions and should be performed before the validation procedure and routine analysis. For the system to be considered reliable and reproducible, it is necessary to perform the following tests, including the repeatability, resolution, asymmetry, number of plates, and retention factor (26). The test was performed by injecting six replicates of the piroxicam solution at the work concentration in different columns technologies. The theoretical plates $(N)$, retention factor $\left(k^{\prime}\right)$, and asymmetry were evaluated according to FDA specifications (26).

Table 1. System suitability parameters analyzed during the HPLC method development

\begin{tabular}{|c|c|c|c|c|c|}
\hline Column & Mobile phase & $k^{\prime 1}$ & $\mathbf{T F}^{2}$ & $N^{3}$ & $\mathbf{R T}^{4}$ \\
\hline Phenomenex ${ }^{\circledR} \mathrm{C} 18(300 \times 3.9 \mathrm{~mm} ; 10 \mu \mathrm{m})$ & $\begin{array}{l}\text { Methanol and citrate-phosphate buffer } \\
\qquad(60: 40 ; \mathrm{v} / \mathrm{v})\end{array}$ & 1.35 & 1.14 & 3418 & $3.5 \mathrm{~min}$ \\
\hline Shimadzu $^{\circledR} \mathrm{C} 18(150$ x $4.6 \mathrm{~mm} ; 5 \mu \mathrm{m})$ & $\begin{array}{l}\text { Acetonitrile and triethylamine solution } 0.3 \% \\
\qquad(30: 70 ; \mathrm{v} / \mathrm{v})\end{array}$ & 2.41 & 1.01 & 6979 & $6.8 \mathrm{~min}$ \\
\hline Phenomenex ${ }^{\circledR}$ C18 (100 x 4.6 mm; $\left.2.6 \mu \mathrm{m}\right)$ & $\begin{array}{l}\text { Acetonitrile and triethylamine solution } 0.3 \% \\
\qquad(30: 70 ; \mathrm{v} / \mathrm{v})\end{array}$ & 1.92 & 1.40 & 5845 & $3.2 \mathrm{~min}$ \\
\hline Phenomenex ${ }^{\circledR} \mathrm{C} 18(100 \times 4.6 \mathrm{~mm}$; monolithic $)$ & $\begin{array}{l}\text { Acetonitrile and triethylamine solution } 0.3 \% \\
\qquad(25: 75 ; \mathrm{v} / \mathrm{v})\end{array}$ & 1.78 & 1.34 & 3558 & $2.7 \mathrm{~min}$ \\
\hline Recomendation $^{5}$ & & $>2$ & $\leq 2$ & $>2000$ & - \\
\hline
\end{tabular}

${ }^{1} k^{\prime}$ (Retention factor), ${ }^{2} \mathrm{TF}$ (tailing factor), ${ }^{3} \mathrm{~N}$ (number of theoretical plates), ${ }^{4} \mathrm{RT}$ (retention time), ${ }^{5} \mathrm{FDA}, 1994$. 
The conditions of the alternative HPLC method were defined considering the ease of use of the methodology and the system suitability parameters presented in Table 1. As can be observed, the conformity chromatographic condition was achieved by using the Shimadzu ${ }^{\circledR}$ C18 column. The use of this column along to a simple mobile phase (without buffer addition), resulted in a relatively short retention time $(6.8 \mathrm{~min})$ and adequate area repeatability (RSD $<2 \%$ ). The optimized conditions of the alternative HPLC method were validated for the analysis of piroxicam in capsules dosage forms, in order to provide capability and application for the QC.

\section{Alternative HPLC method validation}

The method was validated by determining the specificity, linearity, matrix effect, precision, accuracy, LOD, LOQ and robustness following the ICH Q2(R1) guidelines and Brazil RDC 166/2017 (21, 22).

The specificity of the proposed alternative HPLC method was established by forced degradation studies and comparing the chromatogram of placebo solution (representative of all formulations), standard solution, and capsule solution. The results showed that the piroxicam signals had excellent peak purity determined by PDA detector tools, indicating with good confidence the absence of co-eluting peak in their retention times. Under photolytic and thermal conditions, 8.1 and $9.5 \%$ of piroxicam degradation was observed, respectively. The acidic and basic conditions resulted in larger degradation of approximately $80 \%$ in $24 \mathrm{~h}$, and did not produce any detectable degradation product. Exposing the drug under oxidative condition, around $27.5 \%$ degradation was seen, and one major photolytic product was detected at $8.2 \mathrm{~min}$ and two minor degradation products at 3.2 and $3.9 \mathrm{~min}$. Figure 2 presents the chromatograms of degradation studies of piroxicam.

For linearity evaluation, three independent analytical curves with seven concentrations (range of 5-80 $\mu \mathrm{g} / \mathrm{mL}$ ) were constructed. The linearity range was validated at $10-$ $160 \%$ of the target assay concentration. The peak areas of the chromatograms were plotted against the respective concentrations of piroxicam to obtain the analytical curves. The obtained data were statistically analyzed to prove that they met the assumptions for a linear regression. The value of the correlation coefficient (r) calculated was $0.9999(y=21066 x-7695.9)$. Moreover, the regression and lack of fit significances were evaluated by analysis of variance (ANOVA). The regression was highly significant $(P<0.05)$, while the lack-of-fit was not significant $(P>0.05)$, indicating excellent linearity of the method.

The LOD and LOQ were calculated using the mean of the slope and the standard deviation of the intercept of three independent curves, determined by a linear regression line (21). The results for LOD and LOQ were 1.33 and 4.43 $\mu \mathrm{g} / \mathrm{mL}$, respectively.

An estimation of matrix effect was performed by partial $F$-test employing a 5\% significance level and comparing the slopes of the calibration curves performed in placebo solution and in solvent (27). Therefore, two standards lines were prepared for piroxicam: (1) in placebo solution spiked with analytes and (2) in mobile phase. Matrix effect (ME) was calculated according to equation:

ME [\%] = matrix-matched curve slope $\times 100 \%$ solvent curve slope
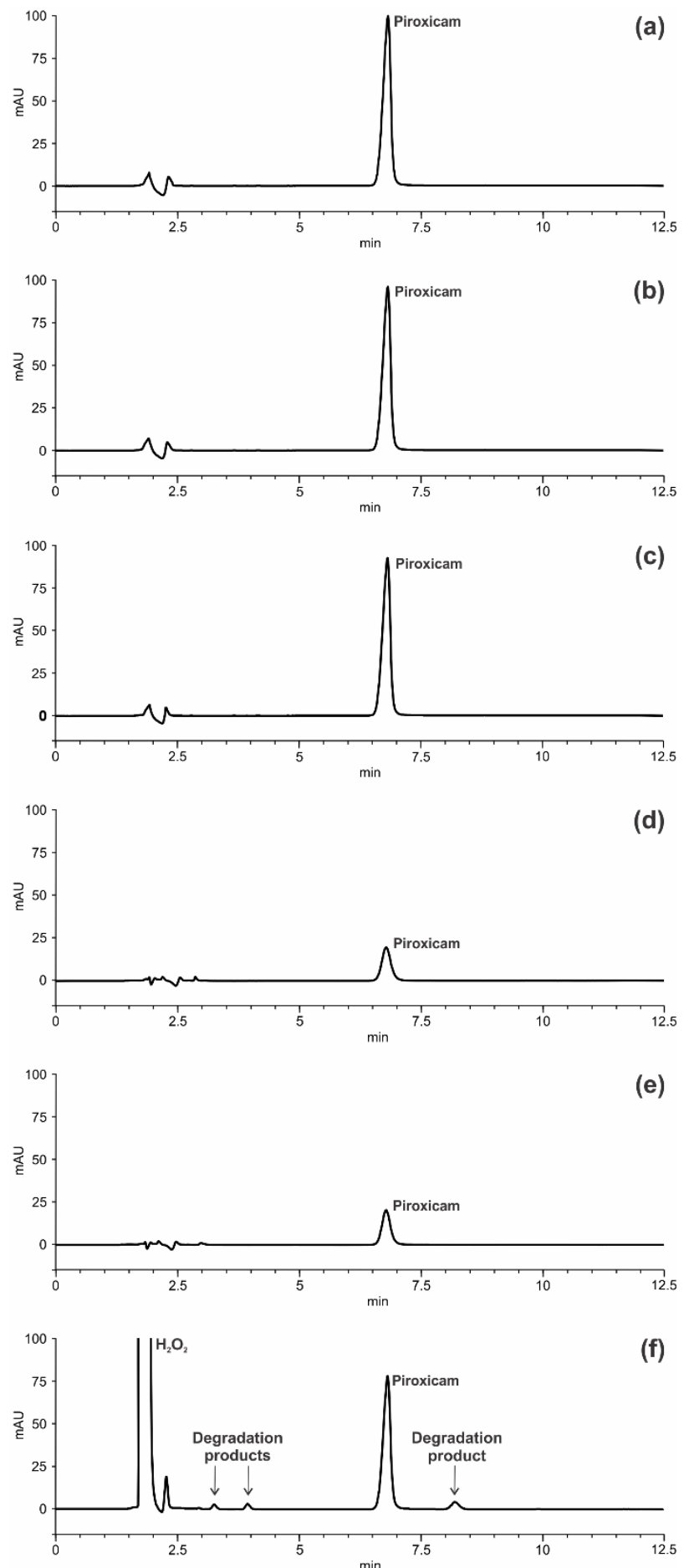

Figure 2. HPLC chromatograms of piroxicam at $50 \mu \mathrm{g} / \mathrm{mL}$ : (a) reference substance solution; (b) photolytic degradation; (c) temperature degradation; (d) acidic degradation; (e) basic degradation; (f) oxidative degradation. Chromatographic conditions: Shimadzu C18 column (150 $\mathrm{mm} \times 4.6 \mathrm{~mm}$ i.d., $5 \mu \mathrm{m}), 30{ }^{\circ} \mathrm{C}$; mobile phase: acetonitriletriethylamine solution $0.3 \%(\mathrm{pH} 3.0)(30: 70 ; \mathrm{v} / \mathrm{v})$; flow rate: 1.0 $\mathrm{mL} / \mathrm{min}$; PDA detection: $248 \mathrm{~nm}$; injection volume: $10 \mu \mathrm{L}$. 
The value of ME below $100 \%$ indicates suppression of signal. Also, for partial $F$-test, $P$-values greater than 0.05 indicate parallelism of lines. Obtained ME value was $102.12 \%$. Additionally, the parallelism of lines was performed by partial $F$-test analysis of the curves presenting $P$-value of 0.30 , over than 0.05 . Therefore, considering excellent parallelism and satisfactory $\mathrm{ME} \%$, the matrix effect was not observed, as required (22).

The precision of the method was demonstrated through repeatability and intermediate precision. Repeatability was examined using six independent sample preparations of the same concentration of piroxicam $(50 \mu \mathrm{g} / \mathrm{mL})$ on the same day and under the same experimental conditions. Intermediate precision is obtained when the assay is performed by multiple analysts using multiple instruments on multiple days in one laboratory (21). In order to study these effects simultaneously, a multivariate approach was used. The considered variables included analysts (1 and 2), samples (1 and 2), and days (1 and 2), and the considered response was the drug assay $(\%)$. A linear model, $y=b 0+b 1 \times 1+b 2 \times 2+b 3 \times 3$, where $y$ is the response to be modeled (assay, \%); $b 0, \ldots, b 3$ are the estimated values for each parameter; $x 1, \ldots, x 3$ are independent variables, was postulated, and a $2^{3}$-full factorial design used to estimate the model coefficients $(28,29)$. The precision evaluated as the method repeatability resulted in a relative standard deviation (RSD) value of $1.21 \%(n=6)$. The analyses of intermediate precision were carried out in a randomized order according to the experimental plan reported in Table 2 . The normal plot of residuals for the response evaluated (assay) is demonstrated in Figure 3. The residuals of a good model are centered around zero with a high proportion (about $95 \%$ ) within \pm 2 , and no pattern to the residuals (31). The respective graph shows random scatter around zero with all points inside the \pm 2 limits. No considered factor was found significant $(P>0.05)$ for the regression model used. The mean values were found to be $104.72 \%$ with an RSD of $3.47 \%(n=24)$. The results were acceptable, indicating an adequate precision of the analytical procedure.

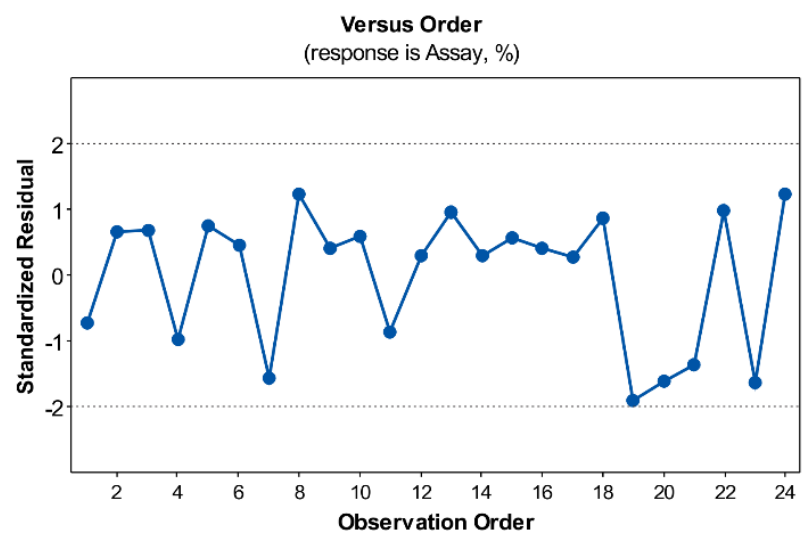

Figure 3. Normal plot of residuals for intermediate precision data (assay) obtained by $2^{3}$-full factorial design $(n=24)$ performed by analysts 1 and 2 , sample 1 and sample 2 , and days 1 and 2.
Table 2. Experimental plan for intermediate precision evaluation of piroxicam and the obtained response.

\begin{tabular}{ccccc}
\hline Run order & Analyst & Sample & Day & Assay $(\%)$ \\
\hline 1 & 2 & 2 & 2 & 102.97 \\
2 & 2 & 1 & 1 & 105.87 \\
3 & 2 & 1 & 2 & 106.57 \\
4 & 2 & 1 & 2 & 100.89 \\
5 & 2 & 2 & 1 & 107.80 \\
6 & 2 & 2 & 2 & 106.97 \\
7 & 1 & 1 & 1 & 97.85 \\
8 & 2 & 1 & 1 & 107.81 \\
9 & 1 & 1 & 2 & 105.82 \\
10 & 1 & 1 & 1 & 105.25 \\
11 & 1 & 2 & 1 & 102.90 \\
12 & 1 & 2 & 1 & 106.90 \\
13 & 1 & 2 & 2 & 109.56 \\
14 & 2 & 1 & 2 & 105.29 \\
15 & 1 & 2 & 1 & 107.81 \\
16 & 1 & 2 & 2 & 107.67 \\
17 & 2 & 2 & 2 & 106.38 \\
18 & 2 & 2 & 1 & 108.12 \\
19 & 2 & 1 & 1 & 97.12 \\
20 & 2 & 2 & 1 & 99.71 \\
21 & 1 & 2 & 2 & 101.63 \\
22 & 1 & 1 & 1 & 106.52 \\
23 & 1 & 1 & 2 & 98.87 \\
24 & 1 & 1 & 2 & 108.59 \\
\hline
\end{tabular}

Accuracy was evaluated by applying the proposed method to the analysis of an in-house mixture of the excipients with known amounts of the drug, to obtain solutions at concentrations of 40,50 and $60 \mu \mathrm{g} / \mathrm{mL}$, equivalent to 80 , 100 and $120 \%$ of the nominal analytical concentration, respectively. Accuracy criteria for an assay method are that the mean recovery will be $100 \pm 2 \%$ at each concentration over the range of $80-120 \%$ of the target concentration. The absolute means obtained for piroxicam are shown in Table 3 with a mean value of $99.12 \%$ and RSDs lower than $1.07 \%$, demonstrating that the method is accurate within the desired range.

Table 3. Accuracy data for proposed HPLC method.

\begin{tabular}{cccc}
\hline $\begin{array}{c}\text { Nominal } \\
\text { concentration } \\
(\boldsymbol{\mu g} / \mathbf{m L})\end{array}$ & $\begin{array}{c}\text { Mean } \\
\text { concentration } \\
\text { found }^{\mathbf{1}}(\boldsymbol{\mu g} / \mathbf{m L})\end{array}$ & $\begin{array}{c}\text { Accuracy } \\
(\boldsymbol{\%})\end{array}$ & $\begin{array}{c}\mathbf{R S D}^{\mathbf{2}} \\
(\boldsymbol{\%})\end{array}$ \\
\hline 40 & 39.69 & 99.24 & 0.41 \\
50 & 49.83 & 99.66 & 0.24 \\
60 & 59.09 & 98.48 & 1.07 \\
\hline
\end{tabular}

${ }^{1}$ Mean of three replicates, ${ }^{2}$ RSD (Relative standard deviation).

The method robustness was investigated employing the Plackett-Burman design. A total of 12 experiments were performed considering four factors at two levels (high and low). The studied factors were: $\mathrm{pH}$ of the mobile phase (4.5-5.5), acid concentration $(0.2-0.4 \%)$, acetonitrile proportion $(28-32 \%)$, flow rate $(0.9-1.1 \mathrm{~mL} / \mathrm{min})$, and oven temperature $\left(32-38^{\circ} \mathrm{C}\right)$, and. The ranges examined were small deviations from the method settings (32). The drug assay $(\%)$ obtained in each experiment were used to statistical analysis. All experiments were performed in 
randomized order. The significance of the effects was evaluated by a Pareto chart of the standardized effects. In Pareto graph (Fig. 4), the ANOVA effect estimates are sorted from the largest absolute value to the smallest absolute value. The magnitude of each effect is represented by a horizontal column. This plot also includes a vertical line to indicate the $P=0.05$ threshold for statistical significance. Effects in which the bars are smaller than the critical t-value were not considered significant and did not affect the response variables (30). So, the method could be considered robust. The validation results were summarized in Table 4.

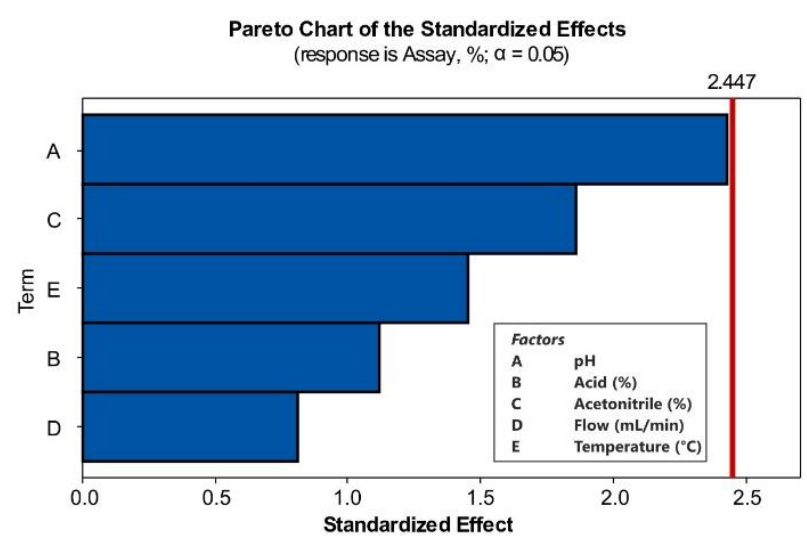

Figure 4. Pareto charts representing the effects of the variables on the piroxicam assay for the robustness test.

\section{Quality control assessment}

Complementarily, the piroxicam capsules were evaluated according to the $\mathrm{BPh}$ requirements. Table 5 shows the data from average weight, disintegration time, dissolution test and content uniformity. Adequate results of content uniformity were achieved for all capsules suppliers, with acceptance values $(<15)$ for the generic product and the masterful pharmacies. The capsules formulations fulfilled the compendial requirement for disintegration time for capsules (< $45 \mathrm{~min})$ and dissolution test $(>70 \%$ of dissolution in $45 \mathrm{~min}$ ). Therefore, the results presented showed that the dosage forms evaluated were in accordance to the official specifications, and these can be suitable for human use.

Table 4. Summary of HPLC method validation results.

\begin{tabular}{cc}
\hline Parameter & Results obtained \\
\hline Linearity $^{1}(r)$ & 0.9999 \\
Repeatability $^{2}\left(\mathrm{RSD}^{5}\right)$ & $1.21 \%$ \\
Intermediate precision $^{3}\left(\mathrm{RSD}^{5}\right)$ & $3.64 \%$ \\
Accuracy $($ recovery $)$ & $99.12 \%$ \\
Limit of detection $(\mu \mathrm{g} / \mathrm{mL})$ & 1.33 \\
Limit of quantitation $(\mu \mathrm{g} / \mathrm{mL})$ & 4.43 \\
Specificity & acceptable \\
Matrix effect & acceptable \\
Robustness & acceptable \\
\hline
\end{tabular}

${ }^{1} n=3$ determinations, ${ }^{2} n=6$ determinations, ${ }^{3} n=18$

determinations, ${ }^{4} n=3$ determinations at each concentration, ${ }^{5} \mathrm{RSD}$ (Relative standard deviation)

\section{Sample analysis}

For assay evaluations, the $\mathrm{BPh}$ recommends an average content between $95 \%$ and $105 \%$ on the declared value of the drug. Thus, the content assessment was performed by compendial UV and HPLC methods and alternative HPLC method. All results were within specifications. Additionally, the statistical analysis (ANOVA) showed non-significance difference for piroxicam content in the same formulation $(\mathrm{P}>0.05)$ and for all formulation when analyzed joinly by different assay piroxicam methods $(F$ calculated $=0.24<F$ critical $=4.26 ; P=0.05)$, as shown in Table 6.

Table 5. Quality control tests of piroxicam capsules.

\begin{tabular}{|c|c|c|c|c|c|}
\hline Product formulation & \multicolumn{2}{|c|}{ Weight variation } & $\begin{array}{l}\text { Disintegration } \\
\text { (min) }\end{array}$ & $\begin{array}{c}\text { Dissolution } \\
(\%)\end{array}$ & $\begin{array}{c}\text { Content uniformity } \\
\left(\mathrm{AV}^{1}\right)\end{array}$ \\
\hline Generic product (A) & 309.8 & 4.20 & 5 & 94.5 & 3.28 \\
\hline Masterful pharmacie (B) & 93.3 & 4.10 & 2 & 105.1 & 0.84 \\
\hline Masterful pharmacie (C) & 97.8 & 2.58 & 5 & 80.1 & 0.84 \\
\hline Masterful pharmacie (D) & 99.0 & 1.88 & 3 & 90.2 & 2.43 \\
\hline Limits $^{2}$ & \multicolumn{2}{|c|}{$\begin{array}{l}\geq 300 \mathrm{mg}: \pm 7.5 \% \\
<300 \mathrm{mg}: \pm 10 \%\end{array}$} & $<45$ & $>70$ & $<15$ \\
\hline
\end{tabular}

${ }^{1}$ Acceptance value, ${ }^{2}$ Brazilian Pharmacopeia, 2019.

Table 6. Piroxicam assay results obtained by alternative HPLC method and Brazilian compendial HPLC and UV methods.

\begin{tabular}{|c|c|c|c|c|c|c|}
\hline \multirow[b]{2}{*}{ Product } & \multicolumn{2}{|c|}{ Compendial UV ${ }^{1}$ (Method I) } & \multicolumn{2}{|c|}{ Compendial HPLC $^{1}$ (Method II) } & \multicolumn{2}{|c|}{ Alternative HPLC (Method III) } \\
\hline & $\operatorname{Assay}^{2}(\%)$ & $\operatorname{RSD}^{3}(\%)$ & $\operatorname{Assay}^{2}(\%)$ & $\operatorname{RSD}^{3}(\%)$ & $\operatorname{Assay}^{2}(\%)$ & $\operatorname{RSD}^{3}(\%)$ \\
\hline $\mathrm{A}$ & 104.5 & 1.60 & 104.6 & 2.12 & 101.9 & 0.48 \\
\hline B & 102.3 & 0.88 & 102.8 & 0.61 & 102.3 & 0.97 \\
\hline $\mathrm{C}$ & 99.8 & 0.96 & 97.3 & 3.26 & 99.5 & 1.03 \\
\hline $\mathrm{D}$ & 97.1 & 1.72 & 89.4 & 1.95 & 94.3 & 1.25 \\
\hline
\end{tabular}

${ }^{1}$ Brazilian Pharmacopeia, 2019, ${ }^{2}$ Mean of three replicates, ${ }^{3}$ RSD (Relative standard deviation). 


\section{Conclusions}

The alternative HPLC method is rapid, selective, with a simple sample preparation procedure and presenting a low use of polluting reagents and very short analysis time. As previously seen, the proposed method was successfully validated following the guideline's requirements. The alternative HPL method showing adequate results of specificity, linearity, matrix effect, precision, accuracy, and robustness, confirming the stability-indicating capability, without any interference from the excipients and degradation products. Therefore, the proposed method was successfully applied for quantitative analysis of piroxicam in pharmaceutical formulations with advantages when compared to $\mathrm{BPh}$ methods, which leads to an affordable method and represents an improvement for the QC and stability studies of piroxicam products.

\section{Acknowledgements}

The authors wish to thank CNPq, FAPERJ and PIBICUFRJ for the financial support.

\section{Conflict of interest}

The authors declare no conflicts of interest.

\section{References}

1. Brazilian Pharmacopeia. 6th. Edition. Brazilian Health Regulatory, 2019.

2.United States Pharmacopeia. USP 43-NF 38. Rockville: The United States Pharmacopoeial Convention, 2020.

3. Richards JA, Cole DA, Hickey RJ, Sokol LS. High performance liquid chromatography assay for piroxicam in pharmaceutical products. J Chromatogr Sci. 1987; 25(7): 292-295.

4. Bartsch H, Eiper A, Kopelent-Frank H. Stability indicating assays for the determination of piroxicamcomparison of methods. J Pharm Biomed Anal. 1999; 20(3): 531-541.

5. Basan H, Goger NG, Ertas N, Orbey MT. Quantitative determination of piroxicam in a new formulation (piroxicam- $\beta$-cyclodextrin) by derivative UV spectrophotometric method and HPLC. J Pharm Biomed Anal. 2001; 26(2): 171-178.

6. Savaser A, Karata A, Özkan Y, Yüksel N, Özkan SA, Baykara T. Validated LC determination of the piroxicam- $\beta$-cyclodextrin inclusion complex in tablets and in human plasma. Chromatographia. 2004; 59: 555560 .
7. Kurakula M, Mohd AB, Rao PA, Diwan PV. Estimation of piroxicam in proliposomal formulation using RP HPLC method. Int J Chem Anal Sci. 2011; 2(9): 11931196.

8. Abdulkarim MF, Abdullah GZ, Sakeena MHF, Chitneni M, Yam MF, Mahdi ES, et al. Modification and validation of an HPLC method for quantification of piroxicam. Int J Drug Deliv. 2011; 3(1): 51-54.

9. Khan IU, Ashfaq M, Razzaq SN, Mariam I. Simultaneous determination of piroxicam and paracetamol in pharmaceutical formulations using stability indicating HPLC method. J Liq Chromatogr R T. 2013; 36(10): 1437-1450.

10. John P, Azeem W, Ashfaq M, Khan IU, Razzaq SN. Stability indicating RP-HPLC method for simultaneous determination of piroxicam and ofloxacin in binary combination. Pak J Pharm Sci. 2015; 28(5): 1713-1721.

11. Dragomiroiu G, Cimpoieşu A, Ginghina O, Baloescu C, Barca M, Popa DE, et al. The development and validation of a rapid HPLC method for determination of piroxicam. Farmacia. 2015; 63: 123-131.

12. Fenner H. Comparative biochemical pharmacology of the oxicams. Scand J Rheumatol. 1987; 65: 97-101.

13. Olkkola KT, Brunetto AV, Mattila MJ. Pharmacokinetics of oxicam nonsteroidal antiinflammatory agents. Clin Pharmacokinet. 1994; 26(2): 107-120.

14. Parisotto G, Souza JS, Ferrão MF, Furtado JC, Molz RF. Análise exploratória aplicada no estudo de medicamentos contendo piroxicam. Rev Bras Cienc Farmac. 2005; 41(4): 499-505.

15. Xu S, Rouzer CA, Marnett LJ. Oxicams, a class of NSAIDs and beyond. IUBMB Life. 2014; 66(12): 803-811.

16. Pulpeiro OG, Pérez YS, Mishing M, Thanh TD. Desarrollo y optimización de una jalea de piroxicam 0,5\%. Rev Cuba Farm. 2009; 43(4): 4-19.

17. Littlejohn EA, Monrad SU. Early diagnosis and treatment of rheumatoid arthritis. Prim Care Clin Office Pract. 2018; 45: 237-255.

18. Jug M, Laćan MB, Kwokal A, Čižmek BC. Influence of cyclodextrin complexation on piroxicam gel formulations. Acta Pharm. 2005; 55: 223-36.

19. Amorim SR, Klier AH, Angelis LH. Controle de qualidade na indústria farmacêutica: identificação de substâncias por espectroscopia no infravermelho. Braz J Pharm. 2013; 94(3): 234-242. 
20. Shaaban H. New insights into liquid chromatography for more eco-friendly analysis of pharmaceuticals. Anal Bioanal Chem. 2016; 408(25): 6929-6944.

21. International Conference on Harmonization (ICH) of Technical Requirements for the Registration of Pharmaceutical for Human Use. Validation of Analytical Procedures: Text and Methodology Q2(R1). Geneva, Switzerland, 2005. 17p.

22. Agência Nacional de Vigilância Sanitária (Anvisa). Resolução RDC n ${ }^{\circ} 166$ de 27 de julho de 2017. Dispõe sobre a validação de métodos analíticos e dá outras providências. Brasília, Brazil: Diário Oficial da União; 2017.

23. Bakshi M, Singh S. Development of validated stability-indicating assay methods-critical review. J Pharm Biomed Anal. 2002; 28(6): 1011-1040.

24. Holm R, Elder DP. Analytical advances in pharmaceutical impurity profiling. Eur J Pharm Sci. 2016; 87: 118-135.

25. Ramachandra B. Development of impurity profiling methods using modern analytical techniques. Crit Rev Anal Chem. 2017; 47(1): 24-36.

26. Food and Drug Administration (FDA). Reviewer Guidance: Validation of Chromatographic Methods. Silver Spring, USA, 1994. 33p.

27. Aszyk J, Kot J, Tkachenko Y, Woźniak M, BoguckaKocka A, Kot-Wasik A. Novel liquid chromatography method based on linear weighted regression for the fast determination of isoprostane isomers in plasma samples using sensitive tandem mass spectrometry detection. J Chromatogr B Analyt Technol Biomed Life Sci. 2017;1051: 17-23.

28. Srinubabu G, Raju CAI, Sarath N, Kumar PK, Rao JVLN. Development and validation of a HPLC method for the determination of voriconazole in pharmaceutical formulation using an experimental design. Talanta. 2007; 71(3): 1424-1429.

29. Sangoi MS, Todeschini V, Steppe M. Determination of fesoterodine in a pharmaceutical preparation by a stability-indicating capillary zone electrophoresis method. J AOAC Int. 2013; 96(6): 1308-1314.

30. Vanaja K, Rani RHS. Design of experiments: concept and applications of Plackett-Burman design. Clin Res Regul Aff. 2007; 24(1): 1-23.

31. Sangoi MS, Todeschini V, Steppe M. Fesoterodine stress degradation behavior by liquid chromatography coupled to ultraviolet detection and electrospray ionization mass spectrometry. Talanta. 2011; 84(4): 1068-1079.
32. Heyden, YV, Nijhuis A, Smeyers-Verbeke J, Vandeginste, BGM, Massart DL. Guidance for robustness/ruggedness tests in method validation. $\mathbf{J}$ Pharm Biomed Anal. 2001; 24(5-6): 723-753. 